\title{
Adiponectin: Obesity and Development of Different
} Diseases

\author{
Q. F. B. Amado Israel de la Cruz Galindo', \\ Jonnathan Guadalupe Santillán Benítez ${ }^{1^{*}}$ and Enrique Morales Avila ${ }^{1}$ \\ ${ }^{1}$ Faculty of Chemistry, Autonomus University of the State of México, Paseo Colón S/N, Residencial \\ Colón, 50120, Toluca de Lerdo, México.
}

Authors' contributions

This work was carried out in collaboration between all authors. Author QFBAICG designed the study, performed the statistical analysis, wrote the protocol, and wrote the first draft of the manuscript.

Authors JGSB and EMA managed the analyses of the study through the PRODEP project DSA / 103.5 / 16/10569. Author JGSB managed the literature searches. All authors read and approved the final manuscript.

Article Information

DOI: $10.9734 / A R R B / 2017 / 36281$

Editor(s):

(1) George Perry, Dean and Professor of Biology, University of Texas at San Antonio, USA.

Reviewers:

(1) Mohamed M. Abdel-Daim, Suez Canal University, Egypt.

(2) Mra Aye, Melaka Manipal Medical College, Melaka, Malaysia. Complete Peer review History: http://www.sciencedomain.org/review-history/20952

Review Article

Received 21 ${ }^{\text {st }}$ August 2017 Accepted $6^{\text {th }}$ September 2017 Published $13^{\text {th }}$ September 2017

\begin{abstract}
Adiponectin is an adipokine abundantly expressed in adipose tissue, which has been well characterized, demonstrating its beneficial effect on human health, circulates in the bloodstream in various isoforms, playing different roles in the balance of energy homeostasis. Adiponectin is an insulin sensitizing hormone that exerts its action through AdipoR1, AdipoR2 and T-cadherin receptors. AdipoR1 is abundantly expressed in muscle, whereas AdipoR2 is expressed predominantly in the liver. Adiponectin is inversely proportional to obesity, diabetes and other states of insulin resistance; this review presents current findings regarding regulation, production and biological effects. Adiponectin acts by activating AMPk (AMP-activated protein kinase) and thus the enzymatic modulation so that the signaling pathways play an important role in the regulation, in addition to the above it has been demonstrated that the deregulation in the biogenesis and function of the miRNAs contributes to the appearance and development of diverse diseases.
\end{abstract}

${ }^{*}$ Corresponding author: E-mail: jonnathangsb@yahoo.com.mx; 
Keywords: Adiponectin; adipokine; obesity; AdipoR1; AdipoR2.

\section{ABBREVIATIONS}

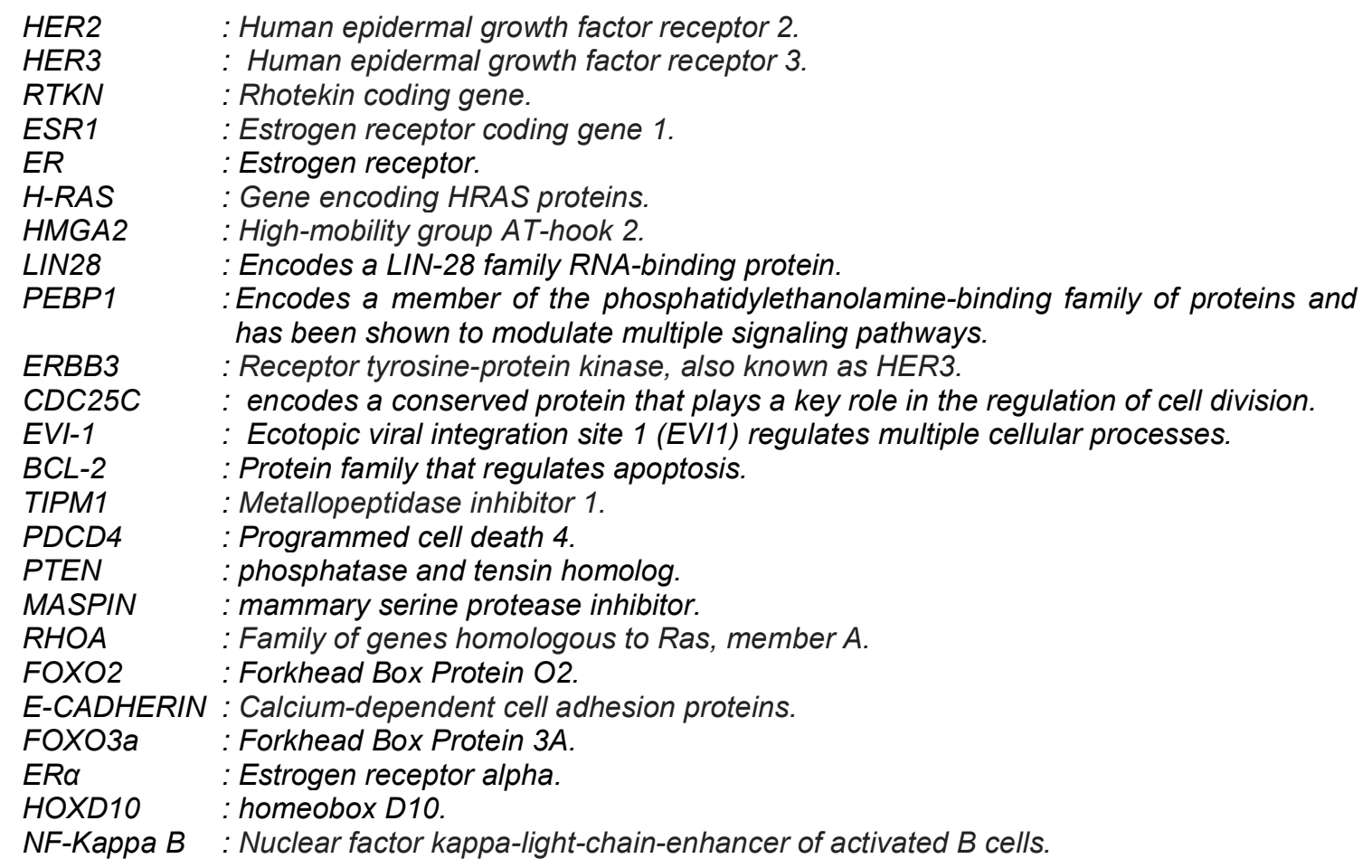

\section{INTRODUCTION}

Obesity is a multifactorial disease produced by the interaction of genetic and environmental factors, caused by lifestyle, characterized by an excessive increase of body fat, produced by an imbalance between ingestion and energy expenditure [1,2]. Obesity has become a public health problem worldwide and its prevalence has increased dramatically in developed and developing countries [2,3]. In this sense, Mexico ranks second in the world prevalence of obesity, where over $70 \%$ of the adult population is overweight and obese, and resulting in economic and public health repercussions [4].

Epidemiological studies have shown that due to the physiological condition that occurs in obesity, it is a risk factor for the development of different diseases, such as cardiovascular, diabetes mellitus, hypertension and different types of cancer, including breast cancer $[1,5]$. In this sense, accumulation of fat causes a deregulation in the production of adipokines which contributes strongly to the onset of obesity related to the development of various diseases, the indisputable protagonist in the pathophysiological process of these diseases is adipose tissue, which is an endocrine organ that produces biologically active molecules defined as "adipokines", involved in the homeostasis of various physiological processes [6,7]. Therefore, alterations in adipose tissue, causes changes in the serum concentrations of adipokines, [6] and against this background, much of the scientific research is directed towards the understanding of the pathological mechanisms of obesity, allowing to establish clear associations between biochemical and anthropometric indicators with the risk of complications derived from obesity. However, an emerging field is the strong relationship between adipokine serum concentrations, particularly adiponectin, with obesity and its involvement in pathophysiological processes [8].

\section{OVERVIEW OF ADIPONECTIN}

Adiponectin, one of many hormones secreted by adipose tissue, was characterized in the 1990s and has received various names according to the description of various research groups [9]. Plasma concentrations of adiponectin in the human are $\sim 5-30 \mu \mathrm{g} / \mathrm{ml}$, this is one of the most 
abundant proteins in circulation $(0.01 \%$ of total proteins) [10]. The biological effects of adiponectin not only depend on blood concentrations, but also important the expression of different isoforms of receptors in different tissues [11].

Adiponectin plays critical roles in metabolism, regulation and maintenance for energy throughout the body, the main target organs are liver and skeletal muscle, however, during the last few decades numerous studies have shown that adiponectin exerts several effects on other organs in different contexts [12] (Fig. 1).

Adiponectin is a $30 \mathrm{kDa}$ protein, composed of 244 amino acids and encodes the long arm of chromosome 3 (locus 3q27). The adiponectin gene consists of 3 exons and 2 introns, structurally containing 4 domains $[15,16]$, it is synthesized as a single subunit and by processes of hydroxylation and glycosylation, various isoforms circulating in the plasma as trimer (low molecular weight LMW), hexamers (MMW average molecular weight) or multimers (high molecular weight HMW) are originated. The monomer form lacks biological activity, whereas HMW is the main active form, and is strongly associated with insulin resistance, metabolic syndrome and cardiovascular disease $[15,16,17,19]$.

The action of adiponectin is mediated by 3 types of receptors: AdipoR1, AdipoR2 and T- Cadherin. The first two consist of 7 transmembrane domains, with the internal $\mathrm{N}$-terminal region and the outer C-terminal region, structurally and functionally different from the G- protein coupled receptor family $[15,20]$. AdipoR1 is abundantly expressed in skeletal muscle and endothelial cells, AdipoR2 is expressed predominantly in the liver. The third is T-cadherin, lacking a transmembrane domain and exhibiting affinity for MMW and HMW isoforms, furthermore involved in cell adhesion and calcium-mediated cellular interactions [14,16,20,21].

\subsection{Signaling Routes}

AdipoR1 and ADipoR2 receptors are able to bind to adiponectin, their subsequent signaling is mediated primarily by AMPK phosphorylation and subsequent activation of mTOR (mammalian Target of Rapamycin), PI3k (phosphoinositide-3kinases) / AKT (protein kinase B), MAPK, PPAR- $\alpha$ (peroxisome proliferator-activated receptor alpha), STAT3 (Signal transducer and activator of transcription 3) and NK-kß (nuclear factor kappa- light-chain-enhancer of activated $B$ cells). AMPK is activated by the adapter protein APPL-1 (adaptor protein, phosphotyrosine interaction, $\mathrm{PH}$ domain and leucine zipper containing 1) and kinase $\beta 1$ (LKB1), the activity of LKB1 (liver kinase B1) depends on the interaction with two proteins STE 20 (STRAD) and MO25, this complex phosphorylates AMPK and regulates several pathways, such as apoptosis, proliferation, angiogenesis and energy metabolism. AMPK phosphorylates the TSC2 (Tuberous Sclerosis Complex 2) protein, which negatively regulates protein synthesis and cell proliferation. Adiponectin also affects PI3K / AKT signaling, which is involved in cell growth and proliferation, AKT phosphorylates TSC2 which in turn stimulates mTOR signaling by neutralizing the effects of activated AMPK. In treatment with adiponectin in breast cancer cells the phosphorylation of $\mathrm{PI} 3 \mathrm{~K}$ and AKT induces the activation of AMPK and suppresses the mTOR pathway thereby inhibiting cell growth. Low doses of adiponectin inhibit ERK1 (extracellular signal-regulated kinases) / 2 signaling and reduce viability in breast cancer cells, and adiponectin induces cell cycle arrest through down-regulation of $\mathrm{C}$-myc, cyclin $\mathrm{D}$, and $\mathrm{Bcl}$ levels. Increases the expression of P53 (cellular tumor antigen), P21 (cyclin-dependent kinase inhibitor 1) and Bax [22,23,24,25,26].

\subsection{Adiponectin Regulation}

White adipose tissue, under normal physiological conditions, controls the use of substrates in other tissues by releasing hormones such as adiponectin that is transported through the bloodstream to other organs, where through signaling pathways mediated by their receptors, they activate key enzymes of lipid and glucose metabolism [27]. Both adiponectin receptors (Adipor1 and Adipor2), are capable of binding to adiponectin; Its subsequent signaling is mediated, mainly by the phosphorylation of AMPK and the activation of the activated receptor of peroxisome alpha proliferator (PPAR), in order to exert modifications in the metabolism of glucose and lipids of liver and muscle cells, as well as in inflammatory processes, vascular endothelial injury, and some are associated with intracellular signaling such as APPL1. In this context, signaling networks play an important role in regulation, activating AMPK and thereby modulating enzymatic activity at the posttranscriptional level; and acting on gene expression through the PPARS nuclear receptors. Similarly, the release of this adipokine 
has a paracrine effect on the adipocytes themselves, in which activation of AMPK also occurs, thus establishing a self-regulation of this organ $[27,28]$.

As mentioned above, the control of energy metabolism falls to several molecular and cellular systems, which interact in a coordinated way establishing a network of communication between different organs. This explains the impact of a disturbance in one of them on the whole organism, endocrine-metabolic disorders such as obesity, type II diabetes, heart failure, characterized by important alterations in energy metabolism, are necessarily related to alterations in this energy signaling pathway (Table 1).

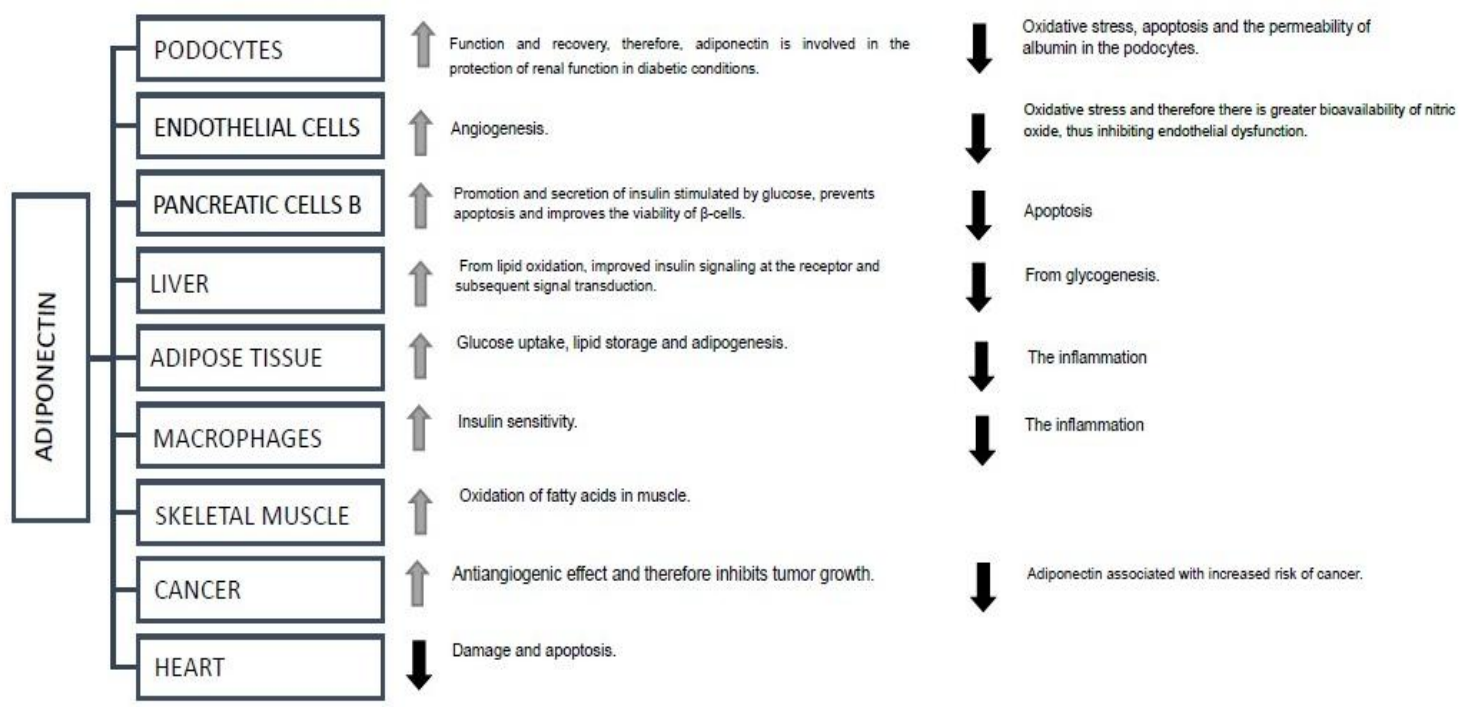

Fig. 1. Adiponectin target tissues and cells $[13,14,15,16,17,18]$ †Increase Decrease

Table 1. Expression inhibitors and main adiponectin signaling ways

Inhibitors of Adiponectin Expression [29, 30,

31, 32, 33]

TNF-a (Tumor Necrosis Factor alpha)

IL-6 (Interleukin 6)

CRP (C- reactive protein)

Insulin

Glucocorticoids

B-adrenergic agonists

AMPK (activaded protein kinase p38)

P38 MAPK (mitogen-activated protein kinases)
Inhibits the production of adiponectin in adipose tissue.

Inhibits the expression and secretion of adiponectin genes in 3T3-L1 adipocytes Inhibits adiponectin mRNA levels in adipose tissue.

Suppresses adiponectin gene expression in adipocytes.

Suppress adiponectin gene expression in adipocytes.

Inhibit adiponectin gene expression.

Inhibitors of the Adiponectin Signaling Ways

DORSOMORPHIN [34]

SB203580 [35]

LY2228820 [36]

VX-702 [37]

LOSMAPIMOD [38]

BIRB796 (P38a) [39]

Skepinone-L(p38 $\alpha)$ [40]

HS-173 (P110 $\alpha)[41]$ 


\begin{tabular}{|c|c|}
\hline \multirow[t]{2}{*}{ PI3K (PI3K: phosphatidylinositol 3-kinase) } & $\begin{array}{l}\text { TGX-221 (P110ß) [42] } \\
\text { CZC244832 (P110Y) [43] }\end{array}$ \\
\hline & CAL-110 (P110ס) [43] \\
\hline \multirow[t]{2}{*}{ AKT ( protein Kinase B) } & A-674563 (AKT 1) [44] \\
\hline & CCT128930 (AKT 2) [44] \\
\hline \multirow{2}{*}{ P53 (Cellular Tumor Antigen) } & $\operatorname{ReACp53}[46]$ \\
\hline & Pifithrin- $\mu[47]$ \\
\hline
\end{tabular}

\section{ADIPONECTIN ASSOCIATED WITH} PHYSIOPATHOLOGICAL PROCESSES

Adiponectin plays an important role against the development of various pathophysiological disorders, including metabolic and vascular diseases, several endocrine pathologies that share some common parameters such as increased insulin resistance, obesity and high blood glucose levels are closely related to low levels of adiponectin. Plasma adiponectin has shown a beneficial effect on human health. However, low levels of adiponectin in pathological conditions such as hypoadiponectinemia, is an important risk factor for the development of various diseases [48] (Table 2).

In contrast to hypoadiponectinemia, hyperadiponectinemia is caused by high concentrations of plasma asiponectin and leads to pulmonary, renal and cardiac diseases (Table 3), however, factors contributing to the development of hyperadiponectinemia remain unknown [62].

Table 2. Diseases associated with hypoadiponectinemia

\section{Obesity}

Diabetes Mellitus Type 2 and Resistance to Insulin

\section{Hypertension}

\section{Dyslipidemia}

Metabolic Syndrome
The expression of adiponectin in adipose tissue and its plasma concentration is reduced in overweight and obese individuals, the plasma adiponectin concentration in addition to being negatively correlated with body mass index, also with the concentration of triglycerides $[49,50]$.

Studies conducted in various populations revealed that low adiponectin concentrations are related to the development of insulin resistance and Type 2 diabetes mellitus [51,52]. There is a positive correlation between hypoadiponectinemia and hypertension, obese individuals with low plasma adiponectin levels are prone to hypertension [53]. Dyslipidemia is a disorder of lipid metabolism characterized by elevated levels of serum triglycerides, low density lipoprotein (LDL cholesterol) and low levels of high density lipoprotein (HDL) cholesterol. Several studies have shown that the level of adiponectin indicates an inverse relationship with the level of low-density lipoprotein, triglycerides and a positive correlation with high-density lipoprotein levels [54].

It is a group of conditions, such as abdominal obesity, insulin resistance, dyslipidemia, hyperglycemia and hypertension, which increase the risk of developing diabetes, stroke and heart disease. Decreased plasma adiponectin levels are associated with an increase in the number of metabolic syndrome components [55]. 


\section{Cardiovascular Disease and Aterosclerosis}

Cancer

Hepatic Disease Non Alcoholic Fat
Low levels of adiponectin play an important role in the development of atherosclerosis and cardiovascular disease, due to the fact that adiponectin plays a protective role in the pathogenesis of vascular diseases by promoting the production of nitric oxide, as well as the inhibition of inflammation and oxidative stress. So adiponectin deficiency shows deterioration of endothelium-dependent vasodilation [56, 57]. Hypoadiponectinenia plays a key role in the development and progression of obesity-related cancer, low plasma levels of adiponectin are directly associated with the risk of developing various types of cancer [58, 59,60].

Disease caused by the deposition of extra fat in liver cells regardless of alcohol consumption and can lead to fibrosis and cirrhosis, adiponectin limits excess lipid deposition in the liver and protects it from inflammation and fibrosis, so Hypoadiponectinemia may play a crucial role in the progression of non-alcoholic fatty liver disease and nonalcoholic steatohepatitis [61].

Table 3. Diseases related to hyperadiponectinemia

\section{Chronic Renal Disease}

\section{Lung Disease}

\author{
Chronic Heart Failure
}

Chronic kidney disease consists of progressive loss of renal function over time and is an independent risk factor for the development of cardiovascular disease. High plasma adiponectin levels were found in patients with chronic kidney disease compared to healthy subjects due to low rate of clearance of adiponectin by the kidney [63].

Hyperadiponectinemia is associated with loss of body weight, systemic inflammation and hyperinflation in patients with COPD [64]. Adiponectin exerts protective effects on $\mathrm{CHF}$ (chronic heart failure) and patients with cardiovascular disease. However, controversy exists over the role of adiponectin and CHF, in some studies, high levels of plasma adiponectin were found in patients with CHF and increased plasma adiponectin levels correlated directly with the severity or mortality in CHF despite the protective effect of high plasma adiponectin on $\mathrm{CHF}$ in mice [65].

\subsection{Strategies for Maintaining Healthy Plasma Adiponectin Levels}

There are several strategies to increase the levels of adiponectin although the difficulty of converting adiponectin into a viable drug has been demonstrated [3]. e.g: PPAR agonists: thiazolidinediones (TZD) but TZD: INT131, induce the expression of adiponectin [7], in this sense a healthy dietary pattern like the mediterranean diet increases the adiponectin plasma levels, in the same context, the activation of AdipoRs is shown one of the most promising therapeutic approaches for treating disorders related to obesity. Nine agonists have recently been demostrated., four of them, mataresinol, arctiin, (-) - arctigenin and gramine, show a high affinity for AdipoR1. Four of these 
compounds, parthenolide, taxifolol, deoxyschizandrin, syringing, show high affinity for AdipoR2 and recently, Okada-lwabu et al. identified a small agonist AdipoRs, AdipoRon which, in vitro, binds to AdipoR1 and AdipoR2 with high affinity $[7,66]$.

\section{REGULATION OF ADIPONECTIN BY MICRORNAs}

MicroRNAs (miRNAs) are small non-coding RNAs that regulate the expression profiles of different genes. Consequently miRNAs are key molecules in the regulation of various processes within which it is possible to cite; proliferation, differentiation, mobility, invasion, cell death, among others. The miRNAs are sequences of a length of 19-25 nucleotides, which regulate the transcription of a white RNA, inhibiting its translation, stabilizing it or leading to its degradation. They are expressed in serum, plasma and other body fluids in a stable form, which makes them attractive for use as biomarkers. Coupled with the above, it is demonstrated that deregulation in the biogenesis and function of miRNAs contributes to the emergence and development of important diseases such as diabetes, cardiovascular diseases and cancer [67].

However, there is currently little data available on the regulation of adiponectin by miRNAs. Adiponectin is a marker protein for the expression and secretion of adipose tissue in adipocyte differentiation. Studies report that miRNAs play an important role in the differentiation of adipocytes and in their function. For example, in adipocyte differentiation, miR-27 expression is downregulated, and its overexpression may specifically inhibit adipocyte differentiation, miR143 expression is upregulated, and the inhibition of its expression may reduce differentiation of the adipocyte. These data suggest that the expression profiles of the miRNAs may change the adipocyte differentiation. This has been tested by Kang M et al. where they report that overexpression of some miRNAs such as miR-2 can significantly promote adipocyte differentiation, and increase the expression of marker genes such as adiponectin. Similarly, in an investigation conducted by Belarbi et al. observed that overexpression of miR-193b, miR-126 and miR26 a increased secretion of adiponectin in human adipocytes $[68,69,70]$.

\section{ROLE OF microRNAS IN BREAST CANCER}

Among the different types of neoplasias, breast cancer is currently the cancer with the highest incidence and mortality in the female population both in Mexico and worldwide. The development of breast cancer is divided into initiation, formation, promotion, progression, metastasis, therapeutic resistance and recurrence of malignant tumors. The miRNAs are part of each of these processes and can act as oncogenes, tumor suppressors or metastatic regulators $[71,72,73]$ (Table 4$)$.

Table 4. Principal miRNAS modulated in breast cancer, white gene and functionality

\begin{tabular}{|c|c|c|}
\hline \multicolumn{3}{|c|}{ Tumor suppressor miRNA } \\
\hline miRNA & Target gen & Associated function in breast cancer \\
\hline $\mathrm{miR}-125 \mathrm{a} / \mathrm{b}$ & HER2, HER3 & Growth dependent anchorage \\
\hline miR-145 & RTKN, Mucin & $\begin{array}{l}\text { Its overexpression inhibits the cell growth } \\
\text { of MCF-7 and induces apoptosis. }\end{array}$ \\
\hline miR-206 & $\begin{array}{l}\text { ESR1, ER (Decreased in ER- } \\
\text { positive breast cancer tissues) }\end{array}$ & ER signaling \\
\hline miR let-7 & H-RAS, HMGA2, LIN28, PEBP1 & Proliferation, differentiation. \\
\hline miR-22 & ERBB3, CDC25C, EVI-1 & $\begin{array}{l}\text { Tumor suppressor and metastasis } \\
\text { inhibitor. }\end{array}$ \\
\hline \multicolumn{3}{|c|}{ miRNA oncogenes } \\
\hline miRNA & Target gen & Associated function in breast cancer \\
\hline miR-21 & $\begin{array}{l}\text { BCL-2, TIMP1, TIMP3, PDCD4, } \\
\text { PTEN, MASPIN }\end{array}$ & Adiponectin inhibitor \\
\hline miR-155 & $\begin{array}{l}\text { RHOA, FOXO2, E-CADHERIN, } \\
\text { FOXO3a }\end{array}$ & Signaling of TGF- $\beta$, inhibitor of apoptosis \\
\hline $\operatorname{miR}-125 b$ & PROAPOPTOTIC Bcl-2 & $\begin{array}{l}\text { MiR125b confers resistance to cancer } \\
\text { cells in the breast cancer to paclitaxel. }\end{array}$ \\
\hline
\end{tabular}




\begin{tabular}{|c|c|c|}
\hline miR-22 & $\mathrm{ER} \alpha$ & $\begin{array}{l}\text { It represses the expression of } \\
\text { estrogen receptor } \alpha\end{array}$ \\
\hline miR-206 & $E R \alpha$ & Induces proliferation \\
\hline miR-10b & HOXD10 & $\begin{array}{l}\text { Metastasis } \\
\text { Its deregulation is involved in breast }\end{array}$ \\
\hline $\mathrm{miR}-146 \mathrm{a} / \mathrm{b}$ & NF-Kappa B & $\begin{array}{l}\text { cancer; Its increase forms part of the } \\
\text { altered expression of BRCA1. }\end{array}$ \\
\hline
\end{tabular}

To date, several studies have been reported to identify differentially regulated miRNAs between the tumor and normal mammary tissue, suggesting its potential use as disease classifiers and prognostic tools in this field. In an analysis of 76 breast tumors and 34 normal specimens, Lorio et al. identified 29 miRNAs that were differentially expressed in breast cancer tissue compared to normal $[72,73,74]$.

\section{CONCLUSION}

Clinical and experimental studies indicate that a normal level of adiponectin helps the body counteract various pathologies related to obesity, which in turn, triggers the onset of metabolic and cardiovascular diseases. Alterations in the plasma adiponectin concentration are a biomarker useful in obesity, diabetes mellitus, dyslipidemia and hypertension, so that several studies suggest that adiponectin supplementation could be used as a potential therapeutic tool, improving the expression and function of receptors when they are present in pathophysiological conditions related to adiponectinemia. Therefore, it is necessary to continue studying the effects and precise mechanisms of action of adiponectin to give way to the development of effective drugs aimed at improving the complications associated with imbalance of this hormone.

\section{COMPETING INTERESTS}

Authors have declared that no competing interests exist.

\section{REFERENCES}

1. Valladares $M$, Corsini G, Romero C. Association between obesity and ovarian cancer. Rev Med Chile. 2014;142:593-598. Spanish.

2. Brito-Nuñez NJ, Alcázar-Carett RJ. Obesity and cardiometabolic risk. CIMEI. 2011;16:106-113. Spanish.

3. Yamauchi T, Kadowaki T. Adiponectin receptor as a key player in healthy longevity and obesity-related diseases. Cell Metabolism. 2013;17:185-186.

4. Dávila-Torres J, González-Izquierdo JJ, Barrera-Cruz A. Overview of obesity in Mexico. Rev Med Inst Mex Seguro Soc. 2015;53(2):240-249. Spanish.

5. Iwabu M, Okada-Iwabu M, Yamauchi T, Kadowaki T. Adiponectin/adiponectin receptor in disease and agin. npj. Angin and Mechanisms of Disease 1. 2015; 15013:1-6.

6. Nava-Santana CA, Guerra-Soto AJ, Mendoza-Vázquez G, Flores-Chavez A, Nava A. Adipokines as mediators in inflammation and the immune system. The Resident. 2013;8:97-105. Spanish.

7. Nigro E, Scudiero O, Monaco ML, Palmieri A, Mazzarella G, Costagliola C, et al. New insight into adiponectin role in obesity and obesity-related diseases. Biomed Res Int. 2014; 2014 article ID658913, 14 pages.

8. Moreno-Mascareño D, Magaña-Gómez JA. Adiponectin, obesity and metabolic syndrome: A relationship to deepen. Rev Med UAS New era. 2012;3:291-39. Spanish.

9. Fasshauer $M$, Blüher $M$. Adipokines in health and disease. Trends Pharmacol Sci. 2015;36:461-470.

10. Fiaschi T, Magherini F, Gamberi T, Modesti PA, Modesti A. Adiponectin as a tissue regenerating hormone: More than a metabolic function. Cell Mol Life Sci. 2014;71:1917-1925.

11. Córdova-Pérez N, Hernández-Valencia M. Adiponectin in different metabolic states. Perinatol Reprod Hum. 2008;22:70-78.

12. Ardenghi G, da Costa JL, Marcadenti A, Lúcia V. Relationship between adiponectin, obesity and insulin resistance. Rev Assoc Med Bras. 2015;61:72-80.

13. Ruan H, Dong L. Adiponectin signaling and function in insulin target tissues. Journal of Molecular Cell Biology. 2016;8:101-109.

14. Ye R, Sherer P. Adiponectin, driver or passenger on the road to insulin sensitivity? Mol Metab. 2013;2:133-141.

15. Yamauchi T, Iwabu M, Okada-Iwabu M, Kadowaki T. Adiponectin receptors: A 
review of their structure, function and how they work. Best Practice \& Amp; Research Clinical Endocrinology \& Amp; Metabolism. 2014;28:15-23.

16. Robinson K, Prins J, Venkatesh B. Clinical review: Adiponectin biology and its role in inflammation and critical illness. Critical Care. 2011;15:221.

17. Dadson K, Liu Y, Sweeney G. Adiponectin action: A combination of endocrine and autocrine/paracrine effects. Front Endocrinol. 2011;2:1-14.

18. Wanees $M$, Mamdouh $M$, Shaban $S$, Ibrahim A, Mohamed MM, Ahmed O, et al. Adipokines: Potential Therapeutic Targets for Vascular Dysfunction in Type II Diabetes Mellitus and Obesity. Journal of Diabetes Research. 2017; Article ID 8095926, 11 pages.

19. Chen X, Wang Y. Adiponectin and breast cáncer. Med Oncol. 2011;28:1288-1295.

20. Dalamaga M, Diakopoulos K, Mantzoros C. The role of adiponectin in cancer: A review of evidence. Endocr Rev. 2012;33: 547-594.

21. Panno ML, Naimo GD, Spina E, Ando S, Mauro L. Different molecular signaling sustaining adiponectin action in breast cáncer. Curr Opin Pharmacol. 2016;31:17.

22. Kadowaki T, Yamauchi T. Adiponectin receptor signaling: A new layer to the current model. Cell Metabolism. 2011;13: 123-124.

23. Jardé T, Perrier S, Vasson MP, CaldefieChézet F. Molecular mechanisms of leptin and adiponectin in breast cáncer. Eur J Cancer. 2011;42:33-43.

24. Khan S, Shukla S, Sinha S, Meeran SM. Role of adipokines and cytokines in obesity- associated breast cancer: Therapeutic targets. Cytokine Growth Factor Rev. 2013;2:503-513.

25. Luo Z, Saha AK, Xiang X, Ruderman NB. AMPK, the metabolic syndrome and cancer. Trends Pharmacol Sci. 2005;26: 69-76.

26. Obeid S, Hebbard L. Role of adiponectin and its receptors in cancer. Cancer Biol Med. 2012;9:213-220.

27. Carvajal KG, Carrillo $S$. molecular signals that modulate energy metabolism: implications in the development of obesity, diabetes and heart disease. Mensaje bioquímico. 2009;33:71-82. Spanish.

28. Godínez-Gutiérrez SA, Valerdi-Contreras L. Obesity: Multiple endocrine resistance.
Revista de Endocrinología y Nutrición. 2012;20:152-168.

29. Makki K, Froguel P, Wolowczuk I. Adipose tissue in obesity-related inflammation and insulin resistance: Cells, cytokines, and chemokines. ISRN Inflamm. 2013;2013: 139239,12 pages.

30. Fasshauer M, Kralisch S, Klier M, Lossner $\mathrm{U}$, Bluher $\mathrm{M}$, Klein $\mathrm{J}$, et al. Adiponectin gene expression and secretion is inhibited by interleukin-6 in 3T3-L1 adipocytes. Biochem Biophys Res Commun. 2003;301: 1045-1050.

31. Yuan G, Chen X, Ma Q, Qiao J, Li R, Li X, et al. C- reactive protein inhibits adiponectin gene expression and secretion in 3T3-L1 adipocytes. J Endocrinol. 2007;194:275-281.

32. Sukumaran S, DuBois D, Jusko WJ, Almon R. Glucocorticoid effects on adiponectin expression. Vitam Horm. 2012;90:163186.

33. Fu L, Isobe $\mathrm{K}$, Zeng $\mathrm{Q}$, Suzukawa $\mathrm{K}$, Takekoshi Z, Kawakami Y. $\beta$-adrenoceptor agonists downregulate adiponectin, but upregulate adiponectin receptor 2 and tumor necrosis factor- $\alpha$ expression in adipocytes. European Journal of Pharmacology. 2007;569:155-162.

34. Liu X, Chhipa RR, Nakano I, Dasgupta B. The AMPK inhibitor compound $C$ is a potent AMPK-independent anti-glioma agent. Mol Cancer Ther. 2014;13:596-605.

35. Düsgún SA, Yerlikaya A, Zeren S, Bayhan Z, Okur E, Boyaci I. Differential effects of p38 MAP kinase inhibitors SB203580 and SB202190 on growth and migration of human MDA-MB- 231 cancer cell line. Cytotechnology. 2017;69:711-724

36. Campbell RM, Anderson BD, Brooks HB, Chan EM, De Dios A, Gilmour R, et al. Characterization of LY2228820 dimesylate, a potent and selective inhibitor of p38 MAPK with antitumor activity. Mol Cancer Ther. 2014;13:364-74.

37. Damjanov N, Kauffman RS, SpencerGreen T. Efficacy, pharmacodynamics, and safety of VX-702, a novel p38 MAPK inhibitor, in rheumatoid arthritis: Results of two randomized, double-blind, placebocontrolled clinical studies. Arthritis Rheum. 2009;60:1232-1241.

38. Watz H, Barnacle H, Hartley BF, Chan R. Efficacy and safety of the p38 MAPK inhibitor losmapimod for patients with chronic obstructive pulmonary disease: $A$ randomized, double-blind, placebo- 
controlled trial. Lancet Respir Med. 2014;2: 63-72.

39. Arthur JS, Ley SC. Mitogen-activated protein kinases in innate immunity. Nat Rev Immunol. 2013;13:679-692.

40. Borst $O$, Walker $B$, Münzer $P$, Russo A, Schmid E, Faggio C, et al. Skepinone-L, a novel potent and highly selective inhibitor of p38 MAP kinase, effectively impairs platelet activation and thrombus formation. Cell Physiol Biochem. 2013;31:914-924.

41. Lee $H$, Jung $K H$, Jeong $Y$, Hong $S$, Hong SS. HS-173, a novel phosphatidylinositol 3- kinase (PI3K) inhibitor, has anti-tumor activity through promoting apoptosis and inhibiting angiogenesis. Cancer Lett. 2013; 328:152-159.

42. Feng $C$, Sun $Y$, Ding $G, W u Z$, Jiang $H$, Wang $L$, et al. PI3K $\beta$ inhibitor TGX221 selectively inhibits renal cell carcinoma cells with both VHL and SETD2 mutations and links multiple pathways. Sci Rep. 2015;5:9465.

43. Mc Namara CR, Degterev A. Smallmolecule inhibitors of the PI3K signaling network. Future Med Chem. 2011;3:549565.

44. Nitulescu GM, Margina D, Juzenas P, Peng Q, Olaru OT, Saloustros E, et al. Akt inhibitors in cancer treatment: The long journey from drug discovery to clinical use (Review). Int J Oncol. 2016;48:869-885.

45. Murphy PJ, Galigniana MD, Morishima $\mathrm{Y}$, Harrell JM, Kwok R, Ljungman M, et al. Pifithrin- $\alpha$ Inhibits p53 Signaling after Interaction of the tumor suppressor protein with hsp90 and its nuclear translocation. J Biol Chem. 2004;279:30195-30201.

46. Soragni A, Janzen DM, Johnson LM, Lindgren AG, Thai-Quynh Nguyen $A$, Tiourin $E$, et al. A designed inhibitor of p53 aggregation rescues p53 tumor suppression in ovarian carcinomas. Cancer Cell. 2016;29:90-103.

47. Green DR, Kroemer G. Cytoplasmic functions of the tumour suppressor p53. Nature. 2009;458:1127-1130.

48. Carranza E, Zuñiga H, Peña C, Huarcaya M, Guerra G, Gordillo G, et al. Adiponectina sérica y su asociación con variables cardiometabólicas en una población adulta de la ciudad de carhuamayo (Junín-Perú).Ciencia e Investigación. 2013;16:24-31. Spanish.

49. Trellakis S, Rydleuskaya A, Fischer C, Canbay A, Tagay S, Scherag A, et al. Low adiponectin, high levels of apoptosis and increased peripheral blood neutrophil activity in healthy obese subjects. Obes Facts. 2012;5:305-18.

50. Tahergorabi Z, Khazaei M, Moodi M, Chamani E. From obesity to cancer: A review on proposed mechanisms. Cell Biochem Funct. 2016;34:533-545.

51. Kishida K, Funahashi T, Shinomura I. Molecular mechanisms of diabetes and atherosclerosis: Role of adiponectin. Endocr Metab Immune Disord Drug Targets. 2012;12:118-31.

52. Silha JV, Krsek M, Skrha JV, Sucharda P, Nyomba B, Murphy LJ. Plasma resistin, adiponectin and leptin levels in lean and obese subjects: Correlations with insulin resistance. Eur J Endocrinol. 2003;149: 331-5.

53. Kim DH, Kim C, Ding EL, Townsend MK, Lipsitz LA. Adiponectin levels and the risk of hypertension: a systematic review and meta-analysis. Hypertension. 2013 Jul; 62: 27- 32 .

54. Izadi V, Farabad E, Azadbakht L. Epidemiologic evidence on serum adiponectin level and lipid profile. Int $\mathrm{J}$ Prev Med. 2013;4:133-140.

55. Sang-A C, Hyung J, Jae-Young C, Seung $H L$, Jae HP, Soon JH, et al. Visceral fat area and serum adiponectin level predict the development of metabolic syndrome in a community-based asymptomatic population. PLoS One. 2017;12: e0169289.

56. Lee S, Kwak HB. Role of adiponectin in metabolic and cardiovascular disease. J Exerc Rehabil. 2014;10:54-59.

57. den Ruijter HM, Pasterkamp G, de jager SC. Adiponectin Regulation in Cardiovascular Disease. Arterioscler Thromb Vasc Biol. 2014;34:2180-2181.

58. Vega-Malagón G, Ávila-Morales J, GarcíaSolís $\mathrm{P}$, Camacho-Calderón N, BecerrilSantos A. Obesity and its relation to breast cancer in a mexican population. European Scientific Journal. 2014;10:132-140. Spanish.

59. Macis D, Guerrieri-Gonzaga A, Gandini S. Circulating adiponectin and breast cancer risk: A systematic review and metaanalysis. International Journal of Epidemiology. 2014;43:1226-1236.

60. Kelany OE, Khaled HE, El-Nahla AM, Abdelrazek HMA, Abdel-Daim MM. Hepatoprotective and metabolic effects of dietary soy phytoestrogens against hyper caloric diet in cyclic female wistar rats is 
mediated through estradiol receptors. Biomed Pharmacol J. 2017;10(3).

61. Petta S, Gastaldelli A, Rebelos E, Bugianesi E, Messa P, Miele L, et al. Pathophysiology of non alcoholic fatty liver disease. Int J Mol Sci. 2016;17:2082.

62. Hossain MM, Mukheem A, Kamarul T. The prevention and treatment of hypoadiponectinemia-associated human diseases by up-regulation of plasma adiponectin. Life Sci. 2015;135:55-67.

63. Heidari $M$, Nasri $P$, Nasri $H$. Adiponectin and chronic kidney disease; a review on recent findings. J Nephropharmacol. 2015;4:63-68.

64. Garcia P, Sood A. Adiponectin in pulmonary disease and critically ill patients. Curr Med Chem. 2012;19:54935500.

65. Kumada M, Kihara S, Sumitsuji S, Kawamoto T, Matsumoto S, Ouchi N, et al. Association of hypoadiponectinemia with coronary artery disease in men. Arterioscler Thromb Vasc Biol. 2003;23: 85-89.

66. Okada-Iwabu M, Yamauchi $T$, Iwabu M, Honma T, Hamagami K, Matsuda K, et al. A small-molecule AdipoR agonist for type 2 diabetes and short life in obesity. Nature. 2013;503:493-499.

67. Rico-Rosillo MG, Vega-Robledo GB, OlivaRico D. Importancia de los microARN en el diagnóstico y desarrollo de enfermedades. Rev Med Inst Mex Seguro Soc. 2014;52:302-307.

68. Kraus M, Greither T, Wenzel C, BräuerHartmann D, Wabitsch M, Behre HM. Inhibition of adipogenic differentiation of human SGBS preadipocytes by androgenregulated microRNA miR-375. Mol Cell Endocrinol. 2015;414:177-185.

69. Belarbi $\mathrm{Y}$, Mejhert $\mathrm{N}$, Lorente-Cebrián S, Dahlman I, Arner $P$, Rydén $M$, et al. MicroRNA-193b controls adiponectin production in human white adipose tissue. J Clin Endocrinol Metab. 2015;100:E1084 -E1088.

70. Kang M, Yan LM, Zhang WY, Li YM, Tang AZ, Ou HS, et al. Role of microRNA-21 in regulating 3T3-L1 adipocyte differentiation and adiponectin expression. Mol Biol Rep. 2013;40:5027-5034.

71. Tume L, Cisneros C, Sevillano J, PachecoTapia R, Matos D, Acevedo Espinola R, et al. MicroRNA dysregulation in cancer: A therapeutic and diagnostic approach. Mexican Gazette of Oncology. 2016;15: 298-304. Spanish.

72. Ochoa RE, González-Balboa P, GonzálezLozada LE, González-Chávez SA, Fuentes-Corona RE, Barragán-Patraca D. The role of microRNAs (miRNAs) in breast cancer. An Med (Mex). 2014;59:267-270. Spanish.

73. Márquez YV, López AP, Balcázar I, Aristizábal $F$. Biological role and applications of miRNAs in breast cancer. Rev. Colomb. Biotechnol. 2014;16:188202. Spanish.

74. López-Camarillo C, Fonseca-Sánchez MA, Astudillo-de la Vega $H$, Ruiz-García $E$, Guadarrama-Orozco JA, Sánchez-Forgach $E$, et al. MicroRNA: new biomarkers in breast cancer. Rev Mex Mastol. 2014;4: 100-107.

(c) 2017 Galindo et al.; This is an Open Access article distributed under the terms of the Creative Commons Attribution License (http://creativecommons.org/licenses/by/4.0), which permits unrestricted use, distribution, and reproduction in any medium, provided the original work is properly cited.

Peer-review history:

The peer review history for this paper can be accessed here: http://sciencedomain.org/review-history/20952 